\title{
Outcome of allogeneic Hematopoietic Stem Cell Transplantation on Diamond-Blackfan anemia using busulfan-based myeloablative regimen
}

\author{
Maryam Behfar ${ }^{1}$, Lili Koochakzadeh ${ }^{2}$, Nafise Yazdanian $^{1}$, Pourya Salajegheh ${ }^{2}$, \\ Tahereh Rostami ${ }^{1}$, Nazanin Khodayari-Namini ${ }^{2}$ Ardeshir Ghavamzadeh ${ }^{1}$, \\ Amir Ali Hamidieh ${ }^{2,3}$ \\ ${ }^{1}$ Hematology-Oncology and Stem Cell Transplantation Research Center and ${ }^{2}$ Department of Pediatric Hematology and \\ Oncology Children's Medical Center, ${ }^{3}$ Pediatric Cell Therapy Research Center, Tehran University of Medical Sciences; \\ Tehran,Iran.E-mail: aahamidieh@sina.tums.ac.ir
}

Received: 2nd May 2018, Revised: 29th July 2018, Accepted: 1st October 2018

\begin{abstract}
SUMMARY: Behfar M, Koochakzadeh L, Yazdanian N, Salajegheh P, Rostami T, Khodayari-Namini N, Ghavamzadeh A, Hamidieh AA. Outcome of allogeneic Hematopoietic Stem Cell Transplantation on Diamond-Blackfan anemia using busulfan-based myeloablative regimen. Turk J Pediatr 2019; 61: 407-412.
\end{abstract}

\begin{abstract}
Allogeneic Hematopoietic Stem Cell Transplantation (allo-HSCT) is the only known curative option for hematologic manifestations of Diamond-Blackfan anemia (DBA) as a rare inherited bone marrow failure syndrome. This treatment may be considered for DBA patients with corticosteroid-resistance, transfusion dependence, and/or progression to severe aplastic anemia or myelodysplastic syndrome (MDS)/ Acute myleloid leukemia (AML). In this prospective study, 10 pediatric DBA patients (age $<15$ years) who underwent allo-HSCT from HLA-matched donors using non-TBI myeloablative conditioning regimen (intravenous busulfan and cyclophosphamide \pm antithymocyte globulin) during September 2010 to February 2014 are reported. For Graft versus Host Disease (GvHD) prophylaxis cyclosporine A. and a short course of methotrexate were administered. Except one patient who received transplantation from his sibling cord blood, engraftment occurred in all the other patients (9 out of 10 ) with full donor chimerism (>95\%). The median neutrophil and platelet engraftment times were 11 (range, 1013) days and 23 (range, 15-50) days, respectively. Acute GvHD developed in 7 patients. After a median follow-up of 53.3 months, 8 patients are still alive, of whom 7 patients are disease-free. The other two patients died due to grade III-IV acute GvHD. Our data suggests that allo-HSCT using busulan-based non-TBI myeloablative conditioning regimen could be a long-term effective treatment for DBA patients. Early transplantation especially before having multiple transfusions leading to iron overload, particularly from an HLAmatched sibling donor would be associated with favorable outcomes.
\end{abstract}

Key words: Diamond-Blackfan anemia, hematopoietic stem cell transplantation, NonTBI myeloablative conditioning.

Diamond-Blackfan anemia (DBA), also known as congenital erythroid hypoplastic anemia, is a rare inherited bone marrow failure syndrome. DBA is characterized by red blood cell failure, congenital anomalies, mainly craniofacial anomalies, and an increased predisposition to malignancies. DBA affects approximately two to seven per million live births and most commonly presents with severe anemia before the age of 1 year. ${ }^{1,2}$

Autosomal dominant inheritance is the most frequently observed pattern of inheritance in DBA patients. Different studies have shown that DBA is caused by mutations affecting proteins of both small and large ribosomal 
subunits. Mutations in the RPS19 gene on chromosome 19, which occurs in $25 \%$ of patients was first reported in 1999. Since then, the scientists have detected haplo insufficiency of about 10 different ribosomal proteins. ${ }^{1,3}$

Treatment of DBA patients is both conservative and curative. Although nearly $20 \%$ of patients experience spontaneous hematologic remission, the rest require longterm treatment. ${ }^{1}$

Steroids and red cell transfusions are the main forms of therapy. Corticosteroids are the cornerstone of initial therapy in DBA., ${ }^{1,2}$ About $80 \%$ of patients are initially steroid responsive. In steroid-resistant patients chronic red cell transfusion remains as the mainstay of treatment, exposing them to iron overload and allergic reactions. ${ }^{4}$ Allogeneic hematopoietic stem cell transplantation (alloHSCT) is the only known curative treatment for hematologic manifestations of DBA, ${ }^{4-6}$ which could be considered in corticosteroidresistance, transfusion-dependence and the ones with progression pattern to other hematologic diseases such as myelodysplastic syndrome (MDS) or acute myeloid leukemia (AML). ${ }^{2,7,8}$ Allo-HSCT has been reported to result in promising outcomes in DBA patients. ${ }^{6-11}$

In this study, we prospectively analyzed the outcomes of pediatric DBA patients who underwent allo-HSCT using a busulfan-based conditioning regimen in a major Iranian reference HSCT center between December 2010 and February 2014. To the best of our knowledge, this is the first report of DBA patients receiving allo-HSCT in the Middle East region.

\section{Material and Methods}

\section{Study setting and patients}

Between December 2010 and February 2014, 10 pediatric DBA patients underwent alloHSCT at the pediatric department of the Hematology-Oncology Research Center and Stem Cell Transplantation (HORCSCT). Diagnosis in all patients had been confirmed by the bone marrow examination results and also the patients' medical history matched the diagnostic criteria for DBA. ${ }^{1}$ All patients were also screened for possible mutations in ribosomal protein genes which are responsible for some of DBA manifestations. Patients were diagnosed with DBA at the median age of 3 months (range, 1 to 7 months) and the median time to HSCT was 6.5 years (range, 1.5 to 15 years). They were all transfusion-dependent due to steroid-resistance and therefore, as the major complication from transfusions is iron overload, the same as thalassemia patients, they were considered for HSCT. The study protocol was approved by institutional review board and ethical committee of our center (Number: IR.TUMS.VCR.REC.1395.78, Date: 31.5.2010) Informed consent was obtained from parents or legal guardian of the children.

\section{Transplant preparation}

HLA-identical siblings were the preferred donors; however, if HLA-identical sibling was not available, for patients with consanguineous parents, other relatives were also taken into account. In cases where HLA-matched sibling and other relatives could not be found, Iranian and worldwide HLA registries were searched to find a suitable unrelated donor.

All related donors were screened for DBA using clinical and hematological (hemoglobin $\mathrm{F}$ and macrocytosis) evaluation before HCST.

The hematopoietic stem cell (HSC) sources were from bone marrow (BMSC), peripheral blood (PBSC) or cord blood (CBSC).

\section{Transplant procedure}

All patients received a conditioning regimen composed of busulfan and cyclophosphamide with or without antithymocyte globulin (ATG). Busulfan (Busilvex; Pierre Fabre Medicament, Boulogne, France) was administered intravenously (IV) doses were adjusted according to patient's weight (i.e., $1 \mathrm{mg} / \mathrm{kg} / \mathrm{q}$.i.d. for $<9 \mathrm{~kg}, 1.2 \mathrm{mg} / \mathrm{kg} /$ q.i.d. for 9 to $<16 \mathrm{~kg}, 1.1 \mathrm{mg} / \mathrm{kg} /$ q.i.d. for 16 to $23 \mathrm{~kg}$ ) for 4 consecutive days (days -8 to -5 ). Cyclophosphamide was given IV at a dose of $50 \mathrm{mg} / \mathrm{kg}$ for 4 consecutive days (days -4 to -1$)$. For HSCT recipients other than HLA identical sibling, in addition to the mentioned regimen, rabbit ATG (Thymoglobulin; Sanofi Inc., Laval, QC, Canada) was given IV at a 
dose of $2.5 \mathrm{mg} / \mathrm{kg} /$ day from days -5 to -2 .

\section{GvHD prophylaxis}

For GvHD prophylaxis, the patients received cyclosporine A (CsA; $1.5 \mathrm{mg} / \mathrm{kg}$ daily, IV starting on day -1 and then increased to $3 \mathrm{mg} /$ $\mathrm{kg}$ from day +7 for PBSC recipients or day +11 for BMSC and CBSC recipients) plus a short course of methotrexate $\left(10 \mathrm{mg} / \mathrm{m}^{2}\right.$ on day +1 and $6 \mathrm{mg} / \mathrm{m}^{2}$ on days +3 and +6 except for CBSC recipients).

\section{Post-Transplantation Supportive Measures}

All patients were hospitalized in strictly protective isolation and received uniform care. Nutritional support was given through the parenteral route. Cytomegalovirus (CMV) infection was monitored using pp65 antigen assay or CMV DNA PCR assay twice weekly.

To prevent busulfan-induced seizure, phenytoin was given to all patients. Other prophylactic treatments included fluconazole, acyclovir and cotrimoxazole for fungal, viral and Pneumocystis jiroveci infections, respectively.

Using short tandem repeat or fluorescein in situ hybridization assay, hematopoietic chimerism monitoring was performed on days $+15,+30,+60,+90$, and +180 days postHSCT followed by 12,18 , and 24 months postHSCT and on a yearly basis thereafter.

After discharge from hospital, patients were followed up in our HSCT clinic.

\section{Outcomes and definitions}

Neutrophil engraftment was defined as a neutrophil count more than $500 / \mu l$ for at least 3 consecutive days without G-CSF infusion and platelet engraftment was defined as platelet count more than $20,000 / \mu$ l for 7 consecutive days without transfusion support. Primary graft failure was defined as failure to achieve absolute neutrophil count of over $500 / \mu \mathrm{L}$ for 3 consecutive days by the day +42 post-HSCT. ${ }^{12}$ Acute and chronic GvHD were diagnosed and graded according to widely accepted criteria. ${ }^{13,14}$ Full donor chimerism means the presence of more than $95 \%$ of donor's HSCs in the recipient's bone marrow or peripheral blood; while mixed chimerism is the presence of $5-95 \%$ of donor cells and rejection is defined as the presence of less than $5 \%$ of donor cells in recipient's bone marrow or peripheral blood. ${ }^{15}$

\section{Results}

In this study, 10 pediatric DBA patients, who underwent allo-HSCT, with median age of 6.7 (range, 2 to 15 ) years were included. The majority of patients $(80 \%)$ received HSCT from their HLA-identical sibling. The mean serum ferritin level before HSCT was $1070 \mathrm{ng} /$ $\mathrm{ml}$ (range, 580 to 1876). The characteristics of donors and recipients are summarized in Table I.

In PBSC and BMSC settings, a median number of 7.82 (range, 4.95 to 12.14 ) $\times 10^{8} \mathrm{cell} / \mathrm{kg}$ of mononuclear cells and 4.12 (range, 1.78 to $7.5) \times 10^{6} \mathrm{cell} / \mathrm{kg}$ of CD $34^{+}$were infused. For the only two patients who received CB stem cells, the doses of total nucleated cells were 5.17 and $4.68 \times 10^{7}$ cell/kg while the CD34 ${ }^{+}$ cell doses were 3.14 and $2.7 \times 10^{5} \mathrm{cell} / \mathrm{kg}$.

Except one patient who was transplanted from his siblings' cord blood, engraftment occurred in all the other patients (9 out of 10) with full donor chimerism. The median neutrophil and platelet engraftment times were 11 (range, 10 to 13 ) days and 23 (range, 15 to 50) days, respectively.

Table II demonstrates the transplantation outcome. After HSCT, 7 out of 9 engrafted patients developed acute GvHD (5 patients with grade I-II and 2 patients with grade IIIIV) which 5 out of them were transplanted from PBST. All of them were treated according to EBMT treatment guideline. ${ }^{16}$ Five out of 7 patients with acute GvHD had a complete response to first or second-line treatment. Only one patient experienced limited chronic GvHD, and so, he received a short course of IV corticosteroid and responded well to it.

Seizure occurred in one patient whom was later diagnosed with posterior reversible encephalopathy syndrome as corroborated by magnetic resonance imaging. For this patient, anticonvulsive medication was administered to prevent seizure recurrence and cyclosporine A was switched to tacrolimus. To date the 
Table I. Characteristics of Patients and Donors.

\begin{tabular}{lcccccccc}
\hline $\begin{array}{l}\text { Patient } \\
\text { no. }\end{array}$ & Sex & $\begin{array}{c}\text { Age at } \\
\text { diagnosis } \\
\text { (month) }\end{array}$ & $\begin{array}{c}\text { Age at } \\
\text { transplant } \\
\text { (month) }\end{array}$ & RP mutations & $\begin{array}{c}\text { Stem cell } \\
\text { source }\end{array}$ & $\begin{array}{c}\text { Donor age } \\
\text { (year) }\end{array}$ & Dono sex & $\begin{array}{c}\text { Donor- } \\
\text { recipient } \\
\text { relationship }\end{array}$ \\
\hline 1 & M & 3 & 60 & Not found & BM & 26 & F & Mother \\
2 & M & 7 & 84 & RPS26 & CB & - & M & Unrelated \\
3 & M & 4.6 & 156 & RPL11 & PB & 4.6 & F & Sibling \\
4 & M & 1.6 & 138 & Not found & PB & 3.5 & M & Sibling \\
5 & M & 1.2 & 36 & RPS19 & CB & - & F & Sibling \\
6 & M & 1.3 & 48 & RPS19 & BM & 12 & M & Sibling \\
7 & F & 4 & 22 & Not found & PB & 17 & M & Sibling \\
8 & M & 2 & 66 & Not found & PB & 7 & M & Sibling \\
9 & M & 2.5 & 180 & Not found & PB & 21 & M & Sibling \\
10 & M & 3 & 32 & Not done & PB & 22 & F & Sibling \\
\hline
\end{tabular}

$\mathrm{M}=$ male; $\mathrm{F}=$ female; $\mathrm{RP}=$ Ribosomal protein; $\mathrm{BM}=$ Bone marrow; $\mathrm{PB}=$ Peripheral blood; $\mathrm{CB}=$ Cord blood

Table II. Outcome and Complications of Transplantation.

\begin{tabular}{|c|c|c|c|c|c|c|c|c|}
\hline $\begin{array}{l}\text { Patient } \\
\text { no. }\end{array}$ & $\begin{array}{l}\text { Neutrophil } \\
\text { engraftment } \\
\text { (day) }\end{array}$ & $\begin{array}{l}\text { Platelet } \\
\text { engraftment } \\
\text { (day) }\end{array}$ & $\begin{array}{c}\text { Chimerism } \\
(\%)\end{array}$ & $\begin{array}{l}\text { Acute } \\
\text { GvHD } \\
\text { (grade) }\end{array}$ & $\begin{array}{l}\text { Chronic } \\
\text { GvHD }\end{array}$ & $\begin{array}{c}\text { Other } \\
\text { transplant } \\
\text { complications }\end{array}$ & $\begin{array}{l}\text { Follow } \\
\text { up } \\
\text { (Months) }\end{array}$ & outcome \\
\hline 1 & 12 & 22 & $>95$ & II & No & Mucositis & 66 & Alive \\
\hline 2 & 13 & 36 & $>95$ & No & No & Mucositis & 27 & Alive \\
\hline 3 & 12 & 14 & $>95$ & III & No & Mucositis & 4 & Dead \\
\hline 4 & 10 & 19 & $>95$ & No & No & - & 35 & Alive \\
\hline 5 & - & - & $\begin{array}{l}\text { Primary } \\
\text { graft failure }\end{array}$ & NA & No & - & 53 & Alive \\
\hline 6 & 13 & 17 & $>95$ & II & No & $\begin{array}{l}\text { Mucositis } \\
\text { Hemorrhagic } \\
\text { cystitis }\end{array}$ & 57 & Alive \\
\hline 7 & 13 & 15 & $>95$ & II & No & Mucositis & 59 & Alive \\
\hline 8 & 11 & 56 & $>95$ & II & No & PRES & 63 & Alive \\
\hline 9 & 11 & 15 & $>95$ & IV & No & $\begin{array}{l}\text { Hemorrhagic } \\
\text { cystitis }\end{array}$ & 1 & Dead \\
\hline 10 & 11 & 11 & $>95$ & I & $\begin{array}{c}\text { Yes } \\
\text { (limited) }\end{array}$ & $\begin{array}{c}\text { Mucositis } \\
\text { CMV infection }\end{array}$ & 68 & Alive \\
\hline
\end{tabular}

GvHD = Graft versus host disease; PRES = Posterior reversible encephalopathy syndrome, NA= not applicable

patient has remained seizure-free. Just one of the engrafted patients developed CMV infection after HSCT which was treated with gancyclovir and showed a favorable response.

After a median follow-up of 53.3 (range, 27 to 68 ) months, 7 out of 9 engrafted patients are still alive with full donor chimerism, transfusion independence, no symptoms of infection and normal growth pattern according to age. The other two engrafted patients, who were both transplanted from their HLAmatched sibling (PBSC), died following grade III-IV acute GvHD. One of them also developed hemorrhagic cystitis.

For the patient who experienced primary graft failure after receiving his HLA-matched 
sibling CBSC, second course of HSCT was recommended, but his parents did not agree.

It is of note that the age seems to have an impact on the final outcome, as 2 out of 3 patients who were older than 10 years in our cohort died a few months after transplantation due to post-HSCT complications; whereas, 6 out of 7 patients who were under 10 years of age had successful transplantation and are alive at the time of this report. But due to the number of patients this is not enough to derive statistically significant data regarding the age.

\section{Discussion}

Currently, HSCT is the only approved curative treatment for hematological manifestations of DBA patients. ${ }^{4-6,10,17}$ For allo-HSCT preparation, there are two recommended conditioning regimens including non-myeloablative or reduced intensity conditioning regimen (RIC) and myeloablative conditioning regimen (MAC). Although there are several reports on DBA patients that have undergone alloHSCT, there is still no consensus over the best conditioning regimens. Most retrospective studies on DBA patients have reported favorable outcomes from the use of MAC regimen; ${ }^{7,9,10}$ however, some case reports have indicated the success of RIC regimen. ${ }^{18-20}$ In the present study, we reported the long-term outcomes of 10 DBA patients after allo-HSCT using MAC regimen consisting of IV busulfan, cyclophosphamide \pm ATG. Our results show satisfactory primary engraftment rate (90\%) similar to other studies. ${ }^{7,9}$ To our knowledge, in no other study, was IV busulfan given to the all DBA patients for conditioning.

Based on the DBA international clinical consensus conference, for both DBA patients who are steroid-unresponsive or transfusiondependent, HSCT is preferred prior to the age of 10, if an HLA-matched related donor is available. ${ }^{1}$ Although the number of patients in our study is not enough for statistical analysis, it is worth mentioning that the two of the three patient who died were over ten years of age.

Similar to other bone marrow failure syndromes, DBA patients are exposed to toxicities and long-term post-HSCT complications, mainly acute and chronic GvHD. Comparing with other studies, acute GvHD (grades I to IV) was more common in our patients during the postHSCT period $(70 \%$ in our patients versus $57 \%$ reported by Fagioly et al. ${ }^{9}$ and $28 \%$ reported by Roy et al. ${ }^{7}$ ). This difference in findings could be the result of using PBSC more frequently than BMSC as the stem cell source for our patients and also our GvHD prophylaxis regimen. GvHD prophylaxis in other studies was different from the current one. ${ }^{7}$

Different stem cell sources including BMSC, PBSC and CBSC have been used in DBA patients. ${ }^{7-10}$ Although several published studies have reported worse outcome in unrelated $\mathrm{CB}$ HSCT compared to other stem cell sources ${ }^{8,10}$, the number of our patients who underwent HSCT from CBSC was not enough for a reliable judgment.

In a study on 61 patients with DBA who underwent HLA-matched related donor transplantation, Roy et al. ${ }^{7}$ reported that HSCT recipients from HLA-identical sibling donors had better survival compared to alternative donor transplant recipients $(76 \%$ versus $39 \%)$. In our series, satisfying engraftment was observed in all patients undergoing HLAidentical sibling HSCT except in one patient who was transplanted from his siblings' CBSC.

In conclusion, HSCT seems to be a reasonable effective treatment modality for transfusion dependent or corticosteroid resistant DBA patients. Due to the rarity of this disease, further multi-central prospective studies is needed to explore more factors which can have an impact on the outcome of allo-HSCT in DBA patients.

\section{REFERENCES}

1. Vlachos A, Ball S, Dahl N, et al; Participants of Sixth Annual Daniella Maria Arturi International Consensus Conference. Diagnosing and treating Diamond Blackfan anaemia: Results of an international clinical consensus conference. Br J Haematol 2008; 142: 859876.

2. Myers KC, Davies SM. Hematopoietic stem cell transplantation for bone marrow failure syndromes in children. BiolBlood Marrow Transplant 2009; 15: 279-229.

3. Narla A, Vlachos A, Nathan DG. Diamond Blackfan anemia treatment: Past, present, and future. Semin Hematol 2011; 48: 117-123. 
4. Vlachos A,Muir E. How I treat Diamond-Blackfan anemia. Blood 2010; 116: 3715-3723.

5. August CS, King E, Githens JH, et al. Establishment of erythropoiesis following bone marrow transplantation in a patient with congenital hypoplastic anemia (Diamond-Blackfan syndrome). Blood 1976; 48: 491498.

6. Ohga S, Mugishima H, Ohara A, et al; Aplastic Anemia Committee Japanese Society of Pediatric Hematology. Diamond-Blackfan anemia in Japan: Clinical outcomes of prednisolone therapy and hematopoietic stem cell transplantation. Int J Hematol 2004; 79: 22-30.

7. Roy V, Pérez WS, Eapen M, et al; Non-Malignant Marrow Disorders Working Committee of the International Bone Marrow Transplant Registry. Bone marrow transplantation for Diamond-Blackfan anemia. Biol Blood Marrow Transplant 2005; 11: 600608 .

8. Mugishima H, Ohga S, Ohara A, Kojima S, Fujisawa K, Tsukimoto I; Aplastic Anemia Committee of the Japanese Society of Pediatric Hematology. Hematopoietic stem cell transplantation for Diamond-Blackfan anemia: A report from the Aplastic Anemia Committee of the Japanese Society of Pediatric Hematology. Pediatr Transplant 2007; 11: 601-607.

9. Fagioli F, Quarello P, Zecca M, et al. Haematopoietic stem cell transplantation for Diamond Blackfan anaemia: A report from the Italian Association of Paediatric Haematology and Oncology Registry. Br J Haematol 2014; 165: 673-681.

10. Vlachos A, Federman N, Reyes-Haley C, Abramson J, Lipton JM. Diamond-Blackfan anaemiaHematopoietic stem cell transplantation for Diamond Blackfan anemia: A report from the Diamond Blackfan Anemia Registry. Bone Marrow Transplant 2001; 27: 381-386.

11. Bizzetto R, Bonfim C, Rocha V, et al; Eurocord and SAA-WP from EBMT.Outcomes after related and unrelated umbilical cord blood transplantation for hereditary bone marrow failure syndromes other than Fanconi anemia. Haematologica 2011; 96: 134-141.
12. Behfar M, Dehghani SS, Hosseini AS, Jalali A Hamidieh AA, Ghavamzadeh A. Non-total body irradiation myeloablative conditioning with intravenous busulfan and cyclophosphamide in hematopoietic stem cell transplantation for malignant infantile osteopetrosis. Pediatr Transplant 2015; 19: 422-427.

13. Lee SJ, Vogelsang G, Flowers ME. Chronic graftversus-host disease. Biol Blood Marrow Transplant 2003; 9: 215-233.

14. Glucksberg H, Storb R, Fefer A, et al. Clinical manifestations of graft-versus-host disease in human recipients of marrow from $\mathrm{Hl}-\mathrm{A}$-matched sibling donors. Transplantation 1974; 18: 295-304.

15. Hamidieh AA, Pourpak Z, Hosseinzadeh $M$, et al. Reduced-intensity conditioning hematopoietic SCT for pediatric patients with LAD-1: Clinical efficacy and importance of chimerism. Bone Marrow Transplant 2012; 47: 646-650.

16. Apperley J, Masszi T. Graft-versus-host disease. In: Apperley J, Carreras E, Gluckman E, Masszi T, (eds). The EBMT-ESH Handbook on Haematopoietic Stem Cell Transplantation. (6th ed). Paris: European School of Haematology 2012; 217-233.

17. Lipton JM, Atsidaftos E, Zyskind I, Vlachos A. Improving clinical care and elucidating the pathophysiology of Diamond Blackfan anemia: An update from the Diamond Blackfan Anemia Registry. Pediatr Blood Cancer 2006; 46: 558-564.

18. Ostronoff M, Florencio R, Campos G, et al. Successful nonmyeloablative bone marrow transplantation in a corticosteroid-resistant infant with DiamondBlackfan anemia. Bone Marrow Transplant 2004; 34: 371-372.

19. Gómez-Almaguer D, Ruiz-Argüelles GJ, Tarín-Arzaga LC, et al. Reduced-intensity stem cell transplantation in children and adolescents: The Mexican experience. Biol Blood Marrow Transplant 2003; 9: 157-161.

20. Berndt A, Helwig A, Ehninger G, Bornhauser M Successful transplantation of CD34+ selected peripheral blood stem cells from an unrelated donor in an adult patient with Diamond-Blackfan anemia and secondary hemochromatosis. Bone Marrow Transplant 2005; 35: 99-100. 